Article

\title{
Using a Fuzzy Analytic Hierarchy Process to Formulate an Effectual Tea Assessment System
}

\author{
Hwai-Hui Fu *, Yan-Yu Chen and Guan-Jie Wang \\ Department of Business Administration, Shu-Te University, Kaohsiung 82445, Taiwan; \\ wuufuu@yahoo.com (Y.-Y.C.); fuuwuu@yahoo.com (G.-J.W.) \\ * Correspondence: fuhh8696@stu.edu.tw
}

Received: 23 June 2020; Accepted: 27 July 2020; Published: 30 July 2020

\begin{abstract}
Taiwan tea is very famous around the world. This study aims to establish a quantized tea assessment system to increase the credibility of the current tea evaluation mechanism. In this study, a new procedure using a fuzzy analytic hierarchy process integrated with linguistic variables is proposed to set up measurable indicators and determine their weights for a tea evaluation mechanism. An affinity diagram was used to deduce three dimensions (i.e., tea farm management, the tea-making process, and organoleptic evaluation) and 11 evaluation criteria for the construction of the tea assessment system. Sixteen experts, including 10 senior tea farmers and six national tea appraisers, were invited to participate in the one-on-one linguistic questionnaire survey. Analysis of the fuzzy analytic hierarchy process shows that tea farm management gains the most weight (0.533), followed by the tea-making process (0.329), and organoleptic evaluation (0.138). Surprisingly, organoleptic evaluation, as the assessment criteria today, places last in the three evaluation dimensions. Findings of this study can provide the Taiwan Tea Association with insightful information for enhancing the current tea assessment system.
\end{abstract}

Keywords: fuzzy analytic hierarchy process; linguistic variables; affinity diagram; national tea appraisers

\section{Introduction}

Tea drinking has a long and rich social history as it has been deeply embedded in Chinese culture [1]. More than 200 years ago, some tea trees from Fujian Province of China were brought to Taiwan. It was the beginning of the tea culture in Taiwan [2,3]. People enjoy having a cup of tea with their friends, after meals, or even at work [4]. Tea in Taiwan has been represented as a healthy and high-quality drink. Because of Taiwan's unique environment for tea cultivation (e.g., mountain climate, cool moist air, and fertile soil) and modern tea processing techniques for quality control, Taiwanese tea is reputed one of the most valuable in the global market [5].

To enhance the credibility of Taiwan's tea quality, the Taiwan Tea Association periodically hosts tea contests. Tea contests have become the main events of the tea industry in Taiwan. Each year the tea district administration assigns a commission to pick the tea for the contests [6]. In the tea contests, blind tests are employed by using three grams of tea infused with $150 \mathrm{~mL}$ water for six min. The tea appraisers are then asked to report the scores by appearance, taste, aroma, liqueur color, and view of brewed leaf [6]. Unfortunately, such organoleptic evaluation criteria of tea contests are excessively subjective. Safety evaluation of the tea drink (e.g., pesticide residue) and objective evaluation criteria (e.g., sanitary condition of tea processing) seem to be completely ignored in the contests. Therefore, the current study argues that some important evaluation criteria are missing in the current tea contests. To ascertain the missing criteria, this study adopted an expert linguistic questionnaire survey and the fuzzy analytic hierarchy process (fuzzy AHP) to obtain more comprehensive scoring items for the tea contests. 
In literature, fuzzy AHP has been widely used to deal with decision-making problems involving multiple criteria evaluations and obtained quite reliable results [7-10]. Consequently, this study adopted the fuzzy AHP method to assist the Taiwan Tea Association to determine the important dimensions and criteria that are ignored in the current tea contests. The purpose of this study is twofold: (1) to clearly and systematically establish a comprehensive tea quality evaluation framework and (2) to determine appropriate dimensions and criteria weights for tea contests.

\section{Literature Review}

\subsection{Tea Farm Management}

Tea plant growth is affected by conditions in the natural environment such as the temperature, precipitation, light intensity, wind, and soil. Normally, the regions between 45 degrees north latitude and 38 degrees south latitude are suitable for cultivating tea plants [11]. In tropical regions, the tea plant can be grown at altitudes ranging from sea level to $2500 \mathrm{~m}$ [12]. Thus, the plant can be farmed throughout the island of Taiwan, but the best quality teas are those from the mountainous regions which are enshrouded in mist and have cool temperatures. These conditions produce teas that are rich and flavorful but less bitter. Taiwanese high-elevation tea is famous for its unique fruity and creamy character with a long finish that lingers in the throat [13]. Although Taiwan is blessed with unsurpassed natural resources for tea planting, natural environmental factors that influence the quality of the tea must be identified and are described as follows $[12,14,15]$.

- Temperature: The proper growth temperature for tea plants is between 18 and $25^{\circ} \mathrm{C}\left(64.40-77.00^{\circ} \mathrm{F}\right)$. Tea plants grown in the plain under high temperature can grow exuberantly, but the tea quality is not as good as those grown in the mountainous areas with lower temperature and larger variation of day and night temperatures.

- Precipitation: Regions with long drought or annual precipitation of less than $1500 \mathrm{~mm}$ are unsuitable for tea plantations, whereas areas with an even distribution of annual precipitation between 1800 and $3000 \mathrm{~mm}$ are best. Humidity should be at the range between $75 \%$ and $80 \%$; otherwise, it will cause disease and affect plant growth.

- Light intensity: The plant leaves are used to produce tea. Consequently, strength and hours of sunshine directly affect plant growth, leaf color, the chemical composition of tea leaves, and even the tea quality.

- Wind: Moderate wind increases airflow and facilitates leaf transpiration which enables the mass flow of mineral nutrients and water from roots to shoots. Therefore, tea plants in an area with moderate winds can grow strong and healthy. By contrast, gales crush the leaves together with the stems and branches, thereby reducing the quality and quantity of tea.

- Soil: Tea plants require well-drained and porous soil with detritus and mineral sandy loam. Soil $\mathrm{pH}$ influences the solubility and effectiveness of plant nutrient elements and further influences tea plant growth. Thus, soil $\mathrm{pH}$ can be viewed as an indirect factor that influences tea quality.

Each plant has its suitable growing environment, and the tea plant is no exception. Tea plants cultivated in appropriate climate, terrain, and soil will produce a good quality and quantity of tea in return. Therefore, those who want to enter the tea industry should deliberately evaluate the natural environment and propose a cultivation operation plan to ensure business success.

\subsection{Tea Farm Soil Management}

The effectiveness of fertilization for plants highly depends on fertilizer ingredients, location, time, and application rate [16]. Wang [17] indicated that the current tea farm soil fertility has three major deficits: (1) large amounts of chemical fertilizers are used to lower the soil $\mathrm{pH}$ (to less than $\mathrm{pH} 4.0$ ) and this situation is detrimental to tea plant growth; (2) excessive application of lime materials causes the soil $\mathrm{pH}$ to be greater than 5.5, and the latter will lead to tea plant growth that exceeds its 
appropriate growth range; and (3) improper and excessive application of organic fertilizer increases organic contents and a high soil $\mathrm{pH}$ causes excessive accumulation of nutrients in the soil and thus produces unhealthy tea plants.

Although tea plants demand high nutrient levels, continuously using compound fertilizer or plant residue to raise the output of production results in soil acidification and uneven distribution of soil nutrients, thereby further changing the chemical, physical, and microbial soil environment.

Together with the changes in the soil environment, tea farmers perceive that poor plant growth and increasing pests and diseases are caused by nutrient deficiency and thus require intensified fertilization [18]. This situation creates a vicious cycle of destruction. Therefore, those who want to establish a tea plantation should first analyze the soil's chemical, physical, and microbial properties to establish a correct fertilization concept.

\subsection{Pesticide Types and Tea Pesticide Residue}

Per agricultural chemicals regulation law, pesticide is used "to protect agricultural production and ecological environment, prevent and eliminate pests, prevent hazards from agro-pesticides, strengthen agro-pesticide administration, promote the development of agro-pesticide industry, and enhance the safety of agricultural products" [19]. Although most pesticides are used to kill insects, pests, or weeds that are dangerous to plants, they actually cause a certain degree of risk or harm to the human body, animals, and environments [20].

To ensure the safety of tea, pesticide residue inspection is required before the tea enters the market. Chen and Huang [21] found that the reasons for pesticide residue on teas include overdosing, the combined use of pesticides, shortening of the safety interval of pesticide usage, or even use of banned pesticides. Therefore, tea farmers should be cautious in using pesticides to prevent plant disease and understand safe pest control for tea plantations.

\subsection{Tea-Making Process and Its Classification}

The Council of Agriculture [22] reported the main process of tea making is from plucking the fresh tea leaves through fermenting, rolling, and drying tea products. To produce quality tea, only the tender leaves or shoots with two or three leaves and a tip would be plucked. The plucked leaves are spread outdoors to dry by sunshine (i.e., sun withering), fermenting and oxidizing the leaves in the process. The sun-withered leaves are then moved indoors. The indoor withering process requires gently stirring the leaves and adjusting the fermentation degree to trigger the release of a specific aroma and taste from the leaves. When the fermentation reaches a certain degree, the fermented leaves stirred evenly with wave machines are frozen or fired to stop fermentation by destroying the enzyme activity. The processes are called frozen or stirring fixations. After performing frozen or stirring fixation, the rolling process begins. The rolling power and pressure render the leaves crimped and shrunken; consequently, the leaf-sap exudation adheres to the surface of the tea leaves. Finally, tea leaves should be dried under high temperature to maintain the moisture at less than $4 \%$ of the leaves. This process stabilizes the aroma and taste of the leaves and thus enhances tea quality.

Naming and classifying tea by its origin, harvest season, tea tree variety, color, flavor, and production can be achieved in various ways. The most common method of classifying tea is based on the degree of fermentation (i.e., non-fermented, partially fermented, and completely fermented tea) $[13,23]$. Non-fermented tea, famously known as green tea, is totally un-oxidized because it is produced by roasting or pan-firing the leaves (without the withering process) immediately after harvesting. This tea retains much of its original ingredients (e.g., catechin and chlorophyll), natural flavor, and color. Unlike non-fermented tea, partially fermented tea uses the withering and stirring process to render the tea semi-oxidized and to release its special aroma and taste. The color of the tea liquid changes from green to gold or amber. Partially fermented teas that are popular include the Dongding oolongs, Mucha Iron Goddess, and Wen Mountain Pouchong tea. Completely fermented tea, 
with black tea as a representative, is fully oxidized to produce theaflavins and thearubigins, turning the color of tea liquid into red.

\subsection{Organoleptic Evaluation of Tea}

Tea grading relies on organoleptic evaluation for which scientific evaluation is a subsidiary [24]. Organoleptic evaluation discriminates tea appearance, color, aroma, and taste via human visual, olfactory, taste, and tactile responsiveness in judging teas. Conversely, tea appraisal set, tea scale, water quality, water temperature, tea-to-water ratio, and infusion time are requested to be the same for all teas in the contest to produce an accurate and stable tea appraisal [25]. Referring to Pan, Jones, and Lin [26-28], the tea appraisal brewing method can be summarized in the following steps.

- Measure $3 \mathrm{~g}$ of the tea sample, and place it into a $150 \mathrm{cc}$ tea appraisal brewing cup.

- Pour hot water of $100^{\circ} \mathrm{C}$ into the cup, brew for six min, and pour out the tea liquid.

- Observe the tea liquid color first. When the temperature of tea liquid reduces to $40{ }^{\circ} \mathrm{C}$, smell the aroma, and taste it. Each evaluation is limited to 30 cups; otherwise, the temperature of the tea liquid would vary and would result in an unfair evaluation.

- Tea sensory appraisals include "observing tea liquid color," "smelling hot aroma," "observing tea flavor," "smelling warm aroma," "smelling cool aroma," "observing brewed leaves," and "observing appearance".

In practice, liquor color, leaf appearance, aroma, and taste are the fundamental items for organoleptic evaluation. Table 1 summarizes the guidelines of organoleptic evaluation.

Table 1. Organoleptic evaluation of tea in Taiwan.

\begin{tabular}{|c|c|c|}
\hline Item & $\%$ & Guideline \\
\hline Liquor color & $10 \%$ & $\begin{array}{l}\text {-Observe the tea liquid color. Body should be bright and shiny but not turbid. } \\
\text {-Example: bright yellow, brilliantly clear, golden amber, or pure green }\end{array}$ \\
\hline $\begin{array}{l}\text { Leaf } \\
\text { appearance }\end{array}$ & $20 \%$ & $\begin{array}{l}\bullet \text { Observe tea leaf shape, twist tightness, color, and tip. } \\
\bullet \text { Example: grainy, twig, and tender shoots joint; complete leaf with one tip; } \\
\text { and pure green evenly }\end{array}$ \\
\hline Aroma & $30 \%$ & $\begin{array}{l}\text {-Distinguish scent types, strength, richness, purity, and odor. } \\
\text { •Example: a sweet scent assailing the nostrils, tea incense assailing } \\
\text { repeatedly, and lingering tea incense smell and aftertaste }\end{array}$ \\
\hline Taste & $40 \%$ & $\begin{array}{l}\text {-Distinguish tea flavor, mellowness, bitterness, and richness. } \\
\text {-Example: smooth, natural aroma with mellowness and richness, sweet } \\
\text { aftertaste, and unique tea character with a long finish lingering in the throat }\end{array}$ \\
\hline
\end{tabular}

Source: 2017 guideline of the Oolong Tea Competition, Lin (2002; 2004), Tang (2016), Pan (2012), and Jones (2012).

\section{Research Method and Procedure}

In the literature, the FAHP is a predominant approach in constructing an evaluation model [29-31]. Therefore, this study adopted this technique to establish the tea assessment system as comprising the following steps.

\subsection{Step One: Analyzing Problems}

In Taiwan, the current tea contests are fully relying on the tea sensory method without considering tea's origin and production process; therefore, it is important to identify tea appraisal criteria and then construct these criteria into several hierarchical layers as below. 


\section{(1) Identifying tea appraisal dimensions and evaluation criteria: an affinity diagram}

By collecting past tea contest information [13] and synthesizing related references, this study adopted an affinity diagram to deduce the three main dimensions of tea farm management, tea-making process, and organoleptic evaluation. Each dimension contains several evaluation criteria.

\section{(2) Expert recruitment and the hierarchical layer construction: the prototype of the tea assessment system}

To ensure the feasibility of the proposed tea evaluation system, this study invited two Taiwanese tea appraisers to participate in developing the dimensions and criteria of the system. Each expert was asked to evaluate the three dimensions and their associated evaluation criteria (total 11 items) and confirm their mutual independence to reduce the relevance of decision factors for qualifying the premise assumption of FAHP. According to expert domain knowledge and experiences, the wording and the evaluation criteria were modified as shown in Figure 1.

Figure 1 shows the tea evaluation mechanism map, including the three dimensions and 11 evaluation criteria. Tea farm management was chosen in the evaluation mechanism of quality tea because the latter is produced through perfect farm management. Tea farmers should possess comprehensive tea knowledge for the effective control of soil $\mathrm{pH}$, handling of the water supply system, and safe use of pesticides. Moreover, tea production (from withering to drying) was included because such process highly influences tea scent, taste, and quality. Notably, quality tea can only be produced in a hygienic working environment. Normally, the organoleptic evaluation used in each tea contest requires assessment of the tea liquor color, aroma, taste, and appearance.

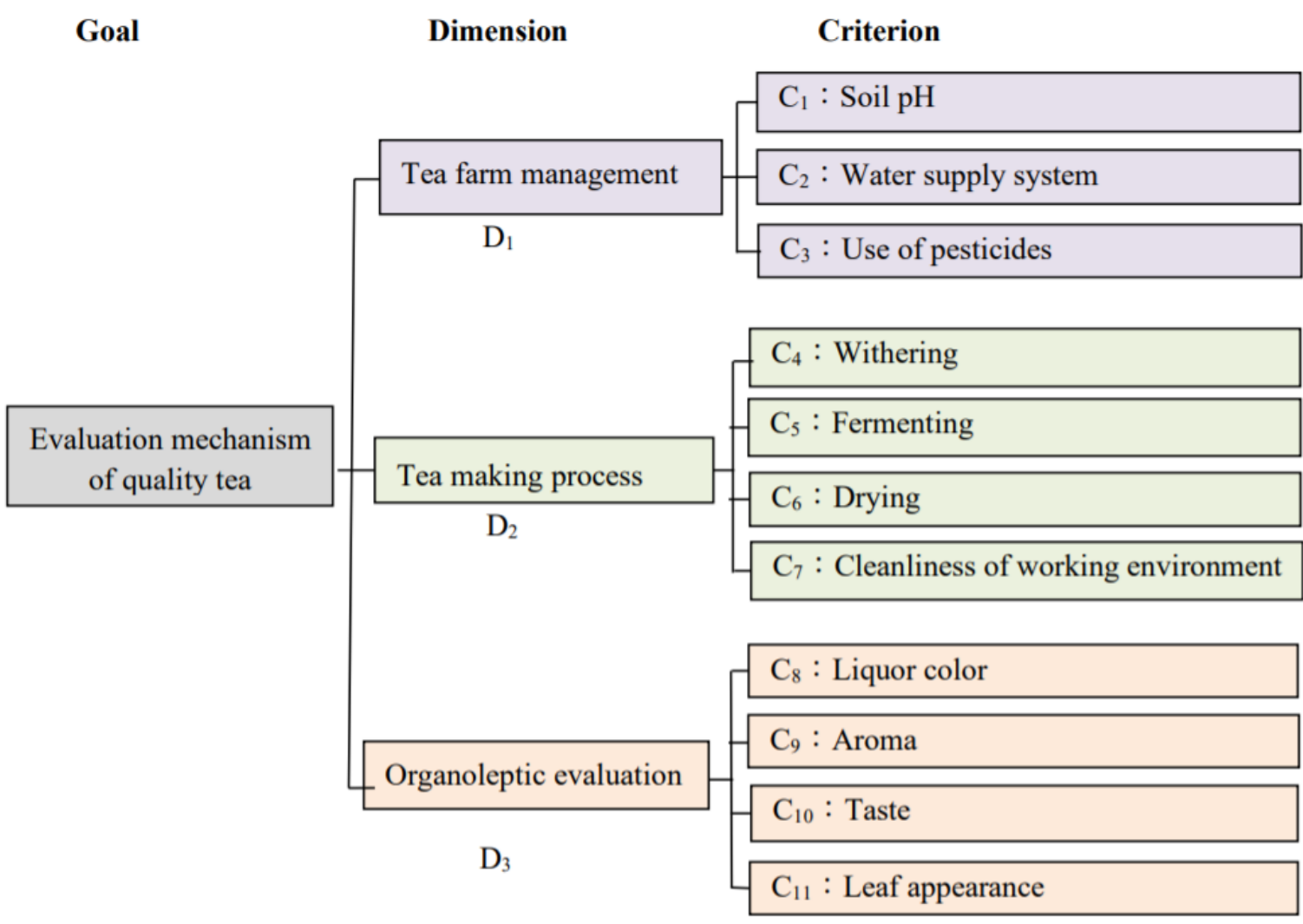

Figure 1. The hierarchical layer construction for the prototype of tea assessment system.

\subsection{Step Two: Dimension and Criterion Comparisons}

To compare the elements of dimension and criterion levels, this study determined their relative importance through a questionnaire survey. 


\section{(1) Linguistic variables and expert questionnaire design}

After the dimensions and evaluation criteria were determined, this study further used linguistic variables to reflect the expert's rating of importance. Linguistic variables can be viewed as "variables whose values are words or sentences in a natural or artificial language" [32]. To compare the importance of each tea evaluation criterion, a five-scale positive/negative linguistic scaling was designed. The positive scaling variables used in this study were "equally important," "moderately important," "important," "very important," and "absolutely important". The negative scaling variables used in this study were "equally important," "not moderately important," "not important," "not very important," and "not absolutely important". Positive scaling suggests that the dimension/criterion is relatively important to the compared dimension/criterion, whereas the negative one indicates that the dimension/criterion is relatively less important to the compared dimension/criterion. The experts were then asked to perform pair-wise comparison between the dimension/criterion and the compared dimension/criterion. Table 2 provides the format of expert questionnaire design with linguistic variables.

\section{(2) Questionnaire survey}

FAHP is applicable to the responses of small and large groups. The size of the FAHP expert group may depend on the nature of the problem and the availability of experts [33]. To reflect the importance levels of dimensions and criteria, a series of interviews was conducted with 16 experts, including 10 representative tea farmers and 6 national tea appraisers. The 10 tea farmers had an average planting seniority of more than 25 years. Six representative national tea appraisers of Taiwan had more than 16 review experiences.

\section{(3) Building pair-wise comparison matrices with fuzzy scales}

As proposed by Saaty [34], the consistency ratio (C.R.) can be used to measure the consistency of decision makers' judgments. The most accepted method to calculate C.R.for fuzzy pair-wise comparison matrices is to transform fuzzy numbers to crisp versions and to proceed as in the ordinary C.R. calculations of AHP [35]. A consistency index should be less than 0.1 for an acceptable comparison [36]. Data collected from the expert questionnaire survey had their consistency index checked first and were then transformed into fuzzy scales (see Table 3) [31,37-39] and assigned into the pair-wise comparison matrices as shown below.

$$
\widetilde{A}=\left[\begin{array}{cccc}
1 & \widetilde{\mathrm{a}}_{12} & \ldots & \widetilde{\mathrm{a}}_{1 \mathrm{n}} \\
\widetilde{\mathrm{a}}_{21} & 1 & \ldots & \widetilde{\mathrm{a}}_{2 \mathrm{n}} \\
\vdots & \vdots & \ddots & \vdots \\
\widetilde{\mathrm{a}}_{\mathrm{n} 1} & \widetilde{\mathrm{a}}_{\mathrm{n} 2} & \ldots & 1
\end{array}\right]=\left[\begin{array}{cccc}
1 & \widetilde{\mathrm{a}}_{12} & \ldots & \widetilde{\mathrm{a}}_{1 \mathrm{n}} \\
1 / \widetilde{\mathrm{a}}_{12} & 1 & \ldots & \widetilde{\mathrm{a}}_{2 \mathrm{n}} \\
\vdots & \vdots & \ddots & \vdots \\
1 / \widetilde{\mathrm{a}}_{1 \mathrm{n}} & 1 / \widetilde{\mathrm{a}}_{2 \mathrm{n}} & \ldots & 1
\end{array}\right]
$$

where

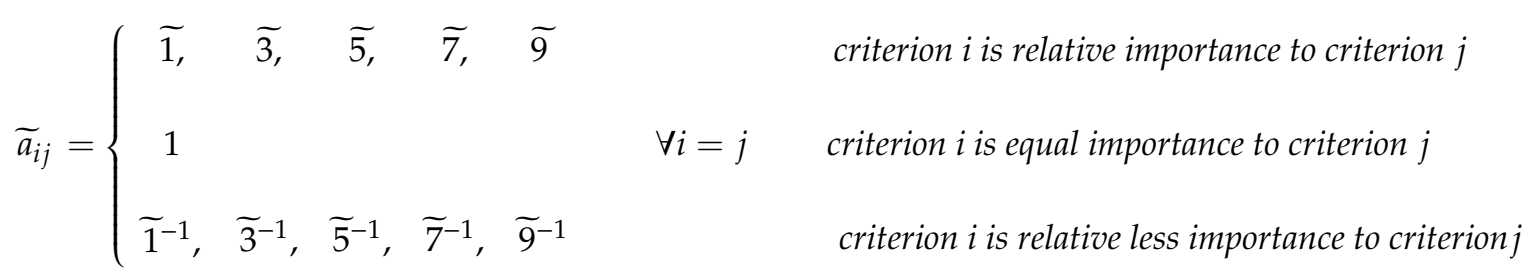

\section{(4) Transforming fuzzy scales into triangular fuzzy numbers}

As shown in Figure 2, this work used a fuzzy five-scale linguistic scaling to weigh the importance of each dimension/criterion. It includes "equally important," "moderately important," "important," "very important," and "extremely important," and each has its related triangular fuzzy numbers $(1,1,3)$, $(1,3,5),(3,5,7),(5,7,9)$, and $(7,9,9)$, respectively. 


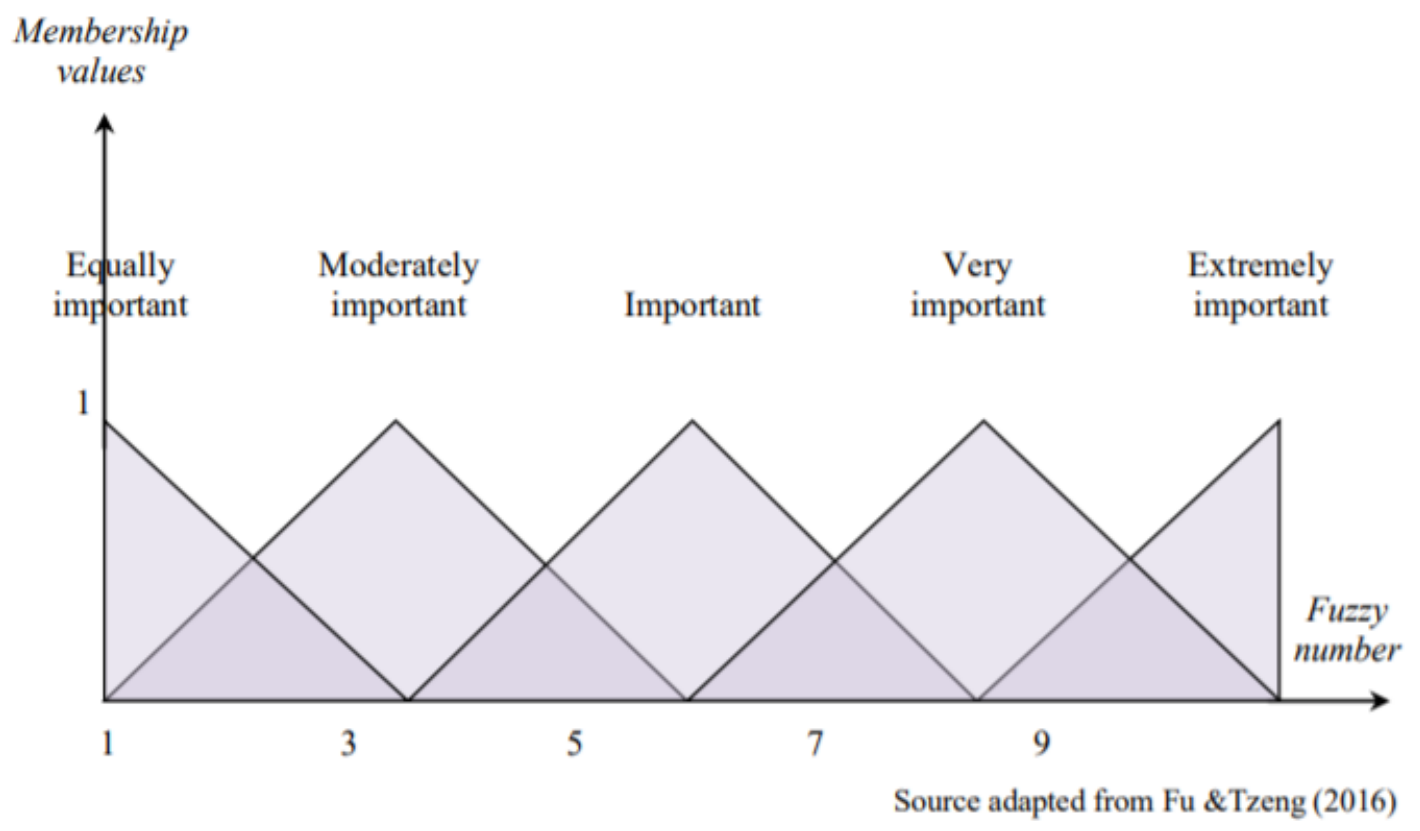

Figure 2. The membership values of linguistic variables for two criteria comparison.

Referring to Mon et al. [39], each scale of fuzzy number is defined by three parameters (i.e., the left, middle, and right points) of the symmetric triangular fuzzy number. This work transformed all fuzzy scales into triangular fuzzy numbers as shown in Table 4.

Table 2. The format of expert questionnaire design with linguistic variables.

\begin{tabular}{|c|c|c|c|c|c|c|c|c|}
\hline \multicolumn{9}{|c|}{ Evaluation Dimension } \\
\hline \multirow{2}{*}{ Dimension } & \multicolumn{4}{|c|}{ Positive } & \multicolumn{3}{|c|}{ Negative } & \multirow{2}{*}{ Compared Dimension } \\
\hline & AI & VI & I & MI & EI & MNI NI & NVI NAI & \\
\hline D1: Tea farm management & & & & & & & & D2: Tea making process \\
\hline D1: Tea farm management & & & & & & & & D3: Organoleptic evaluation \\
\hline D2: Tea making process & & & & & & & & D3: Organoleptic evaluation \\
\hline \multicolumn{8}{|c|}{ Evaluation criteria under D1: Tea farm management } & \\
\hline Criterion & $\mathrm{AI}$ & VI & I & MI & EI & MNI NI & NVI NAI & Compared Criterion \\
\hline C1: Soil pH & & & & & & & & C2: Water supply system \\
\hline C1: Soil pH & & & & & & & & C3: Use of pesticides \\
\hline C2: Water supply system & & & & & & & & C3: Use of pesticides \\
\hline
\end{tabular}

\begin{tabular}{|c|c|c|c|c|c|c|c|c|}
\hline \multicolumn{9}{|c|}{ Evaluation criteria under D2: Tea making process } \\
\hline Criterion & AI & VI & I & MI & EI & MNI NI & NVI NAI & Compared Criterion \\
\hline C4: Withering & & & & & & & & C5: Fermenting \\
\hline C4: Withering & & & & & & & & C6: Drying \\
\hline C4: Withering & & & & & & & & C7: Cleanliness of working environment \\
\hline C5: Fermenting & & & & & & & & C6: Drying \\
\hline C5: Fermenting & & & & & & & & C7: Cleanliness of working environment \\
\hline C6: Drying & & & & & & & & C7: Cleanliness of working environment \\
\hline
\end{tabular}

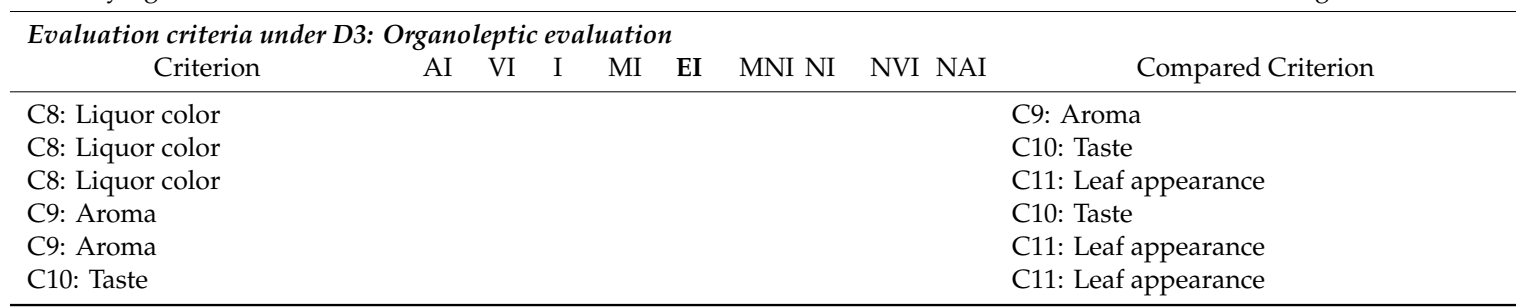

Notes: AI (absolutely important); VI (very important); I (important); MI (moderately important); EI (equally important); NMI (not moderately important); NI (not important); NVI (not very important); NAI (not absolutely important). 
Table 3. Linguistic variables and fuzzy scales.

\begin{tabular}{cccccc}
\hline $\begin{array}{c}\text { Positive } \\
\text { Linguistic Variable }\end{array}$ & Fuzzy Scale & $\begin{array}{c}\text { Negative } \\
\text { Linguistic Variable }\end{array}$ & Fuzzy Scale \\
\hline Equally important & EI & $\widetilde{1}$ & Equally important & EI & $\widetilde{1}^{-1}$ \\
Moderately important & MI & $\widetilde{3}$ & Not moderately important & NMI & $\widetilde{3}^{-1}$ \\
Important & I & $\widetilde{5}$ & Not important & NI & $\widetilde{5}^{-1}$ \\
Very important & VI & $\widetilde{7}$ & Not very important & NVI & $\widetilde{7}^{-1}$ \\
Absolutely important & AI & $\widetilde{9}$ & Not absolutely important & NAI & $\widetilde{9}^{-1}$ \\
\hline
\end{tabular}

Table 4. The triangular fuzzy number of positive/negative linguistic scale.

\begin{tabular}{cccc}
\hline $\begin{array}{c}\text { Fuzzy Scale (from Positive } \\
\text { Linguistic Variable) }\end{array}$ & $\begin{array}{c}\text { Triangular Fuzzy } \\
\text { Number }\end{array}$ & $\begin{array}{c}\text { Fuzzy Scale (from Negative } \\
\text { Linguistic Variable) }\end{array}$ & $\begin{array}{c}\text { Triangular Fuzzy } \\
\text { Number }\end{array}$ \\
\hline$\widetilde{1}$ & $(1,1,3)$ & $\widetilde{1}^{-1}$ & $\left(\frac{1}{3}, \frac{1}{1}, \frac{1}{1}\right)$ \\
$\widetilde{3}$ & $(1,3,5)$ & $\widetilde{3}^{-1}$ & $\left(\frac{1}{5}, \frac{1}{3}, \frac{1}{1}\right)$ \\
$\widetilde{5}$ & $(3,5,7)$ & $\breve{5}^{-1}$ & $\left(\frac{1}{7}, \frac{1}{5}, \frac{1}{3}\right)$ \\
$\widetilde{7}$ & $(5,7,9)$ & $\widetilde{7}^{-1}$ & $\left(\frac{1}{9}, \frac{1}{7}, \frac{1}{5}\right)$ \\
$\widetilde{9}$ & $(7,9,9)$ & $\widetilde{9}^{-1}$ & $\left(\frac{1}{9}, \frac{1}{9}, \frac{1}{7}\right)$ \\
\hline
\end{tabular}

\subsection{Step Three: The Importance Determination}

(1) Aggregating group decision

To aggregate the group decision, this study adopted geometric mean, the most common operation used in fuzzy multiple criteria decision making [40]. The following formula can be used to transfer expert opinions into triangular fuzzy numbers.

$$
\widetilde{a}_{i j}=\left(\widetilde{a}_{i j}^{1} \otimes \vec{a}_{i j}^{2} \otimes \cdots \otimes \widetilde{a}_{i j}^{N}\right)^{\frac{1}{n}}
$$

where

$\widetilde{a}_{i j}$ is the integrated triangle fuzzy umber by $\mathrm{N}$ experts;

$\vec{a}_{i j}^{k}$ is the $i$-th to the $j$-th factor pair comparison by expert $k$.

$\otimes$ is the symbol of matrix multiplication

(2) Calculating geometric mean and fuzzy weight

Buckley [40] suggested using the geometric mean to obtain the fuzzy geometric mean and fuzzy weight of each criterion as indicated below.

$$
\begin{gathered}
\widetilde{r}_{i}=\left(\widetilde{a}_{i 1} \otimes \widetilde{a}_{i 2} \otimes \cdots \otimes \widetilde{a}_{i n}\right)^{\frac{1}{n}} \\
\widetilde{w}_{i}=\widetilde{r}_{i} \otimes\left(\widetilde{r}_{1} \oplus \widetilde{r}_{2} \oplus \cdots \oplus \widetilde{r}_{n}\right)^{-1}
\end{gathered}
$$

where

$\widetilde{a}_{i n}$ is fuzzy comparison value of criterion $i$ to criterion $n$,

$\widetilde{r}_{i}$ is geometric mean of fuzzy comparison value of criterion i to each criterion,

$\widetilde{w}_{i}$ is the fuzzy weight of the i-th criterion, can be indicated by a triangular fuzzy number.

$\oplus$ is the symbol of matrix plus

Hence $\widetilde{w}_{i}=\left(L w_{i}, M w_{i}, U w_{i}\right) . L w_{i}, M w_{i}$, and $U w_{i}$ stand for the lower, middle, and upper values of the fuzzy weight of the $i$-th criterion respectively. 


\subsection{Step Four: Weight Priority by Defuzzification}

Defuzzification is used to renew the fuzzy number into a single crisp value [41]. In the literature, the mean of maximum (MOM) and center of area (COA) convert a fuzzy weight into a non-fuzzy value and have been extensively applied in defuzzification $[29,42,43]$. As the COA method outperforms MOM [44,45], this study used the former to obtain the best non-fuzzy performance value (BNP) by the following equation. The weight of best non-fuzzy performance values $\left(\mathrm{BNP}_{\mathrm{w}}\right)$ are be normalized by BNP.

$$
\begin{aligned}
& \mathrm{BNP}_{\mathrm{i}}=\left[\left(\mathrm{Uw}_{\mathrm{i}}-\mathrm{Lw}_{\mathrm{i}}\right)+\left(\mathrm{Mw}_{\mathrm{i}}-\mathrm{Lw}_{\mathrm{i}}\right)\right] / 3+\mathrm{Lw}_{\mathrm{i}} \\
& \mathrm{BNP}_{\mathrm{w}_{1}}=\mathrm{BNP}_{i} /\left(\mathrm{BNP}_{1}+\mathrm{BNP}_{2}+\cdots+\mathrm{BNP}_{n}\right)
\end{aligned}
$$

\section{Data Analysis}

This study adopted FAHP to formulate the tea assessment system with regard to the evaluation dimensions and criteria. The results of the questionnaire survey provided the values of consistency ratio as less than 0.1 , thereby representing a consistent and acceptable comparison derived from expert opinions. Accordingly the weights of the dimension hierarchy and criterion hierarchy can be analyzed. The two decision-making groups are tea farmer and tea appraiser. The following example demonstrates the computational procedure of the weights of dimensions for the tea-appraiser group:

$$
\begin{aligned}
& \begin{array}{llllllllllllllllll}
\mathrm{D}_{1} & \mathrm{D}_{2} & \mathrm{D}_{3} & \mathrm{D}_{1} & \mathrm{D}_{2} & \mathrm{D}_{3} & \mathrm{D}_{1} & \mathrm{D}_{2} & \mathrm{D}_{3} & \mathrm{D}_{1} & \mathrm{D}_{2} & \mathrm{D}_{3} & \mathrm{D}_{1} & \mathrm{D}_{2} & \mathrm{D}_{3} & \mathrm{D}_{1} & \mathrm{D}_{2} & \mathrm{D}_{3}
\end{array}
\end{aligned}
$$

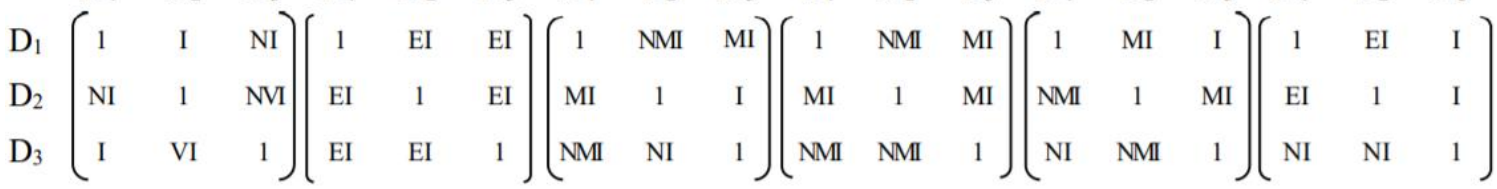

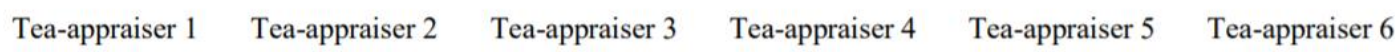

Applying the fuzzy numbers defined in Table 3, we can transfer the linguistic scales to the corresponding fuzzy numbers as follows:

$$
\begin{aligned}
& \begin{array}{llllllllllllllllll}
\mathrm{D}_{1} & \mathrm{D}_{2} & \mathrm{D}_{3} & \mathrm{D}_{1} & \mathrm{D}_{2} & \mathrm{D}_{3} & \mathrm{D}_{1} & \mathrm{D}_{2} & \mathrm{D}_{3} & \mathrm{D}_{1} & \mathrm{D}_{2} & \mathrm{D}_{3} & \mathrm{D}_{1} & \mathrm{D}_{2} & \mathrm{D}_{3} & \mathrm{D}_{1} & \mathrm{D}_{2} & \mathrm{D}_{3}
\end{array}
\end{aligned}
$$

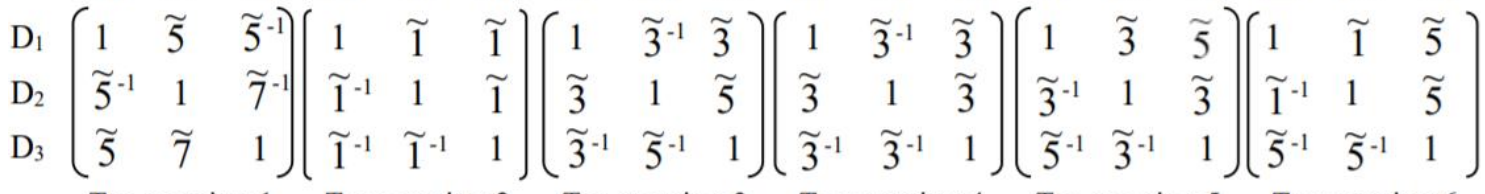

Computing the triangular fuzzy numbers of the tea-appraiser group integration by using the geometric mean method suggested by Buckely (1985), that is: $\widetilde{a}_{i j}=\left(\widetilde{a}_{i j}^{1} \otimes \widetilde{a}_{i j}^{2} \otimes \cdots \otimes \widetilde{a}_{i j}^{6}\right)^{1 / 6}$, for $\widetilde{a}_{12}$ as an example:

$$
\begin{aligned}
\widetilde{a}_{12} & =\left((3,5,7) \otimes(1,1,3) \otimes\left(\frac{1}{5}, \frac{1}{3}, \frac{1}{1}\right) \otimes\left(\frac{1}{5}, \frac{1}{3}, \frac{1}{1}\right) \otimes(1,3,5) \otimes(1,1,3)\right)^{1 / 6} \\
& =\left(\left(3 \times 1 \times \frac{1}{5} \times \frac{1}{5} \times 1 \times 1\right)^{1 / 6},\left(5 \times 1 \times \frac{1}{3} \times \frac{1}{3} \times 3 \times 1\right)^{1 / 6},\left(7 \times 3 \times \frac{1}{1} \times \frac{1}{1} \times 5 \times 3\right)^{1 / 6}\right) \\
& =(0.702,1.089,2.608)
\end{aligned}
$$

We can also obtain the other matrix elements by the same computational procedure; therefore, the synthetic pair-wise comparison matrices of the triangular fuzzy numbers of the tea-appraiser group integration will be constructed as follows: 


\begin{tabular}{|c|c|c|c|c|c|c|c|c|c|}
\hline & \multicolumn{3}{|c|}{$\mathrm{D}_{1}$} & \multicolumn{3}{|c|}{$\mathrm{D}_{2}$} & \multicolumn{3}{|c|}{$\mathrm{D}_{3}$} \\
\hline$D_{1}$ & $(1$ & 1 & 1 & $(0.702$ & 1.089, & $2.608)$ & (1.043, & 1.886 & $3.271)$ \\
\hline $\mathrm{D}_{2}$ & (0.383, & 0.918 , & 1.424) & $(1$ & 1 & 1 & $(0.000$, & 1.783 & 3.004) \\
\hline $\mathrm{D}_{2}$ & $(0.306$ & 0.530 , & 0.959) & $(0.333$ & 0.561 , & $1.000)$ & $(1$ & 1 & 1 \\
\hline
\end{tabular}

Equation (3) can be used to obtain the fuzzy geometric mean $\left.\widetilde{r}_{i}\right)$ of dimensions for the teaappraiser group, that is:

$$
\begin{aligned}
\widetilde{r}_{1} & =\left(\widetilde{a}_{11} \otimes \widetilde{a}_{12} \otimes \widetilde{a}_{13}\right)^{\frac{1}{3}} \\
& =\left((1 \times 0.702 \times 1.043)^{\frac{1}{3}},(1 \times 1.089 \times 1.886)^{\frac{1}{3}},(1 \times 2.608 \times 3.271)^{\frac{1}{3}}\right) \\
& =(0.901,1.271,2.043)
\end{aligned}
$$

Likewise, we can obtain the remaining $\widetilde{r}_{2}$ and $\widetilde{r}_{3}$.

Equation (4) can be used to obtain the fuzzy weights $\left(\widetilde{w}_{i}\right)$ of dimensions for the tea appraiser group, that is:

$$
\begin{aligned}
\widetilde{w}_{1} & =\widetilde{r}_{1} \otimes\left(\widetilde{r}_{1} \oplus \widetilde{r}_{2} \oplus \widetilde{r}_{3}\right)^{-1} \\
& =(0.901,1.271,2.043) \otimes(2.095,3.117,4.653)^{-1} \\
& =(0.901,1.271,2.043) \otimes\left(\frac{1}{4.653}, \frac{1}{3.117}, \frac{1}{2.095}\right) \\
& =(0.194,0.408,0.976)
\end{aligned}
$$

Likewise, we can obtain the remaining $\widetilde{w}_{2}$ and $\widetilde{w}_{3}$.

$$
\begin{aligned}
& \text { fuzzy geometric mean }\left(\tilde{\mathrm{r}}_{\mathrm{i}}\right)
\end{aligned}
$$

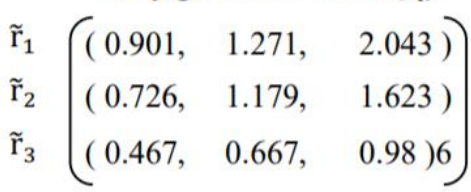

$$
\begin{aligned}
& \text { Sum }=\begin{array}{lll}
2.095 & 3.117 & 4.653
\end{array} \\
& \mathrm{BNP}_{1}=\frac{\left[\left(\mathrm{Uw}_{1}-\mathrm{Lw}_{1}\right)+\left(\mathrm{Mw}_{1}-\mathrm{Lw}_{1}\right)\right]}{3}+\mathrm{Lw}_{1}=\frac{[(0.976-0.194)+(0.408-0.194)]}{3}+0.194=0.526 \\
& \mathrm{BNP}_{\mathrm{w}_{1}}=\mathrm{BNP}_{1} /\left(\mathrm{BNP}_{1}+\mathrm{BNP}_{2}+\mathrm{BNP}_{3}\right)=0.526 /(0.526+0.436+0.262)=0.526 / 1.244=0.43
\end{aligned}
$$
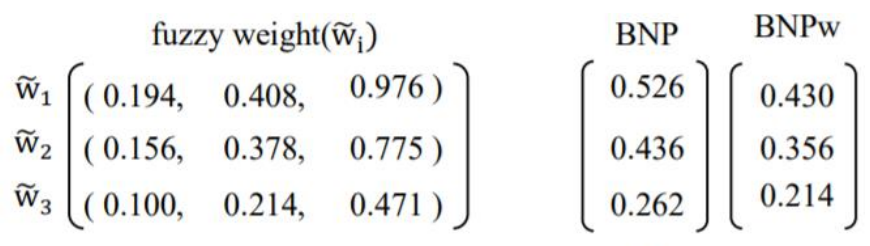

Similarly, the weights for the remaining dimensions and criteria for tea-farmer and tea-appraiser groups can be found as shown in Table 5. The Average column of Table 5 also aggregates the weights of dimensions and criteria for all decision-makers. 
Table 5. Weights of dimensions and criteria for tea-farmer and tea-appraiser groups.

\begin{tabular}{lccc}
\hline \multicolumn{1}{c}{$\begin{array}{c}\text { Dimension } \\
\text { Criterion }\end{array}$} & \multicolumn{2}{c}{ Group Weights } & Overall Weights \\
& Tea-Farmer & Tea-Appraiser & \\
\hline Tea farm management & 0.591 & 0.430 & 0.533 \\
Soil pH & 0.520 & 0.488 & 0.532 \\
Water supply system & 0.106 & 0.334 & 0.171 \\
Use of pesticides & 0.374 & 0.178 & 0.297 \\
Tea making process & 0.305 & 0.356 & 0.329 \\
Withering & 0.503 & 0.508 & 0.507 \\
Fermentation & 0.306 & 0.268 & 0.292 \\
Drying & 0.135 & 0.125 & 0.131 \\
Cleanliness of working environment & 0.056 & 0.099 & 0.070 \\
Organoleptic evaluation & 0.104 & 0.214 & 0.138 \\
Liquor color & 0.130 & 0.090 & 0.114 \\
Aroma & 0.503 & 0.406 & 0.469 \\
Taste & 0.282 & 0.375 & 0.317 \\
Leaf appearance & 0.085 & 0.129 & 0.100 \\
\hline
\end{tabular}

In terms of dimension evaluation, tea farm management with an overall weight of 0.533 should be the first priority in the tea assessment system, followed by tea-making process $(0.329)$ and organoleptic evaluation (0.138). From the perspectives of the tea-farmer group, tea farm management has the highest group weight of 0.591 ; tea-making process (0.305) and organoleptic evaluation (0.104) ranked second and third, respectively. From the perspective of the tea-appraiser group, tea dimension evaluation is sequentially ranked into tea farm management (0.430), tea-making process (0.356), and organoleptic evaluation (0.214). Thus, experts believe that tea farm management should be the focus in the tea assessment, followed by tea-making process and organoleptic evaluation. Surprisingly, organoleptic evaluation, as the current assessment criteria, places last among the three evaluation dimensions. The findings of this study obviously overrule the tea appraisal method of today's tea contests.

Further examining the criteria under each dimension, this study found that soil $\mathrm{pH}$ with an overall weight of 0.532 is the most important criterion for tea farm management, followed by the use of pesticides (0.297), and a water supply system (0.171). The tea-farmer group thought that the order of importance in tea farm management is as follows: soil $\mathrm{pH}(0.520)$, the use of pesticides $(0.374)$, and water supply system (0.106). Conversely, the tea-appraiser group believed that the influences of tea farm management involve soil $\mathrm{pH}(0.488)$, the water supply system (0.334), and the use of pesticides $(0.178)$. That is, tea appraisers claim that the water supply system is more important than the use of pesticides in farm management and affects the quality of tea products. Moreover, both tea-farmer and tea-appraiser groups have reached an agreement regarding the importance ranking of the evaluation criteria under the dimension of the tea-making process. They all agreed that withering with an overall weight of 0.507 is the most important criterion of making quality tea followed by fermentation (0.292), drying (0.131), and the cleanliness of the working environment (0.070). Moreover, the ranking orders of the group weight for each criterion are the same for both groups. Furthermore, the rankings of each criterion's overall weight under the organoleptic evaluation dimension were aroma (0.469), taste (0.317), liquor color (0.114), and leaf appearance (0.100). However, the tea-farmer and tea-appraiser groups hold different opinions regarding the importance of each criterion. For the tea-farmer group, the ranking orders of the criteria under organoleptic evaluation dimension are aroma (0.503), taste (0.282), liquor color (0.130), and leaf appearance (0.085). By contrast, the tea-appraiser group ranks the aroma (0.406) and taste (0.375) first but consider leaf appearance (0.129) as more important than liquor color (0.090). For commercial tea products, aroma and taste might be the main purchase factors, while leaf appearance and liquor color are related to visual aesthetic feeling. The evaluation differentiation between the tea-farmer and tea-appraiser groups may arise from the roles they play in the evaluation system. 


\section{Conclusions, Suggestions and Limitations}

\subsection{Conclusions and Suggestions}

Tea has been recognized as an old and traditional product in Taiwan [2]. Taiwanese tea differs greatly to teas from China in particular. This is mostly due to the soil in which it grows, in high-elevation tea-growing regions throughout the island, and the production techniques used [2,3,5]. Recently, an increasing number of tea types have been launched in the market and flaunted as quality tea, but the quality and taste of the teas vary significantly. Thus, the Association of Taiwan Tea hosts regular tea contests to guarantee tea quality and increase product credibility [46]. Unfortunately, the tea contests in Taiwan rely on the judges' tea appraisals; that is, organoleptic evaluation under ISO 3103. Thus, the judges formulate their assessments on the final tea products to grade teas without knowing its origin. Specifically, the issues of pesticide residues, water supply pollution, and the hygiene of tea making arouse no concern in the tea contests. This omission motivates us to re-examine the current tea appraisal method and formulate an effective tea evaluation system.

Through expert interviews, the results of fuzzy AHP showed that exclusive dependence on organoleptic evaluation to grade tea may cause a loss of objectivity. Therefore, tea farm management and the tea-making process were highly recommended as inclusions in the current tea evaluation system. The new evaluation of tea competitions is demonstrated in Table 6.

Table 6. New evaluation of tea contests in Taiwan.

\begin{tabular}{|c|c|c|c|}
\hline Major Items & $\%$ & Detailed Items & $\%$ \\
\hline \multirow{3}{*}{$\begin{array}{c}\text { Tea farm } \\
\text { management }\end{array}$} & \multirow{3}{*}{$53 \%$} & Soil pH & $53 \%$ \\
\hline & & Water supply system & $17 \%$ \\
\hline & & Use of pesticides & $30 \%$ \\
\hline \multirow{4}{*}{$\begin{array}{c}\text { Tea making } \\
\text { process }\end{array}$} & \multirow{4}{*}{$33 \%$} & Withering & $51 \%$ \\
\hline & & Fermentation & $29 \%$ \\
\hline & & Drying & $13 \%$ \\
\hline & & Cleanliness of working environment & $7 \%$ \\
\hline \multirow{4}{*}{$\begin{array}{l}\text { Organoleptic } \\
\text { evaluation }\end{array}$} & \multirow{4}{*}{$14 \%$} & Liquor color & $11 \%$ \\
\hline & & Aroma & $47 \%$ \\
\hline & & Taste & $32 \%$ \\
\hline & & Leaf appearance & $10 \%$ \\
\hline
\end{tabular}

\section{(1) Tea farm management}

Whether by a senior tea-farmer group or a tea-appraiser group, tea farm management (overall weight $=53 \%$ ) is recognized as the most important factor in the evaluation system. This study suggests that soil $\mathrm{pH}$ (soil $\mathrm{pH}$ test), water supply system (water supply quality test), and the use of pesticides (pesticides residue test) should be evaluated and included in the evaluation system. Particularly, the soil $\mathrm{pH}$ of tea farm management requires emphasis. Unfortunately, considering the mechanism of tea farm management is entirely excluded in today's tea evaluation system.

\section{(2) Tea-making process}

Tea-farmer and tea-appraiser groups believe that evaluation of the tea-making process (overall weight $=33 \%$ ) is superior to that of organoleptic evaluation. Therefore, withering, fermenting, drying, and the cleanliness of the working environment should be considered during the tea-making process. Notably, withering is the first step of the tea-making process. The degree of withering profoundly affects the quality of tea. Thus, tea farmers and tasters claimed that withering is an important part of the advanced tea-making process. 
Organoleptic evaluation (overall weight $=14 \%$ ) has been evaluated as the least important dimension in this study. In this dimension, tea aroma (scent) is the most important criterion for tea-farmer and tea-appraiser groups. In fact, smelling before drinking is a human habit. Thus, tea aroma generates the first impression in tea evaluation. For tea producers, scent should be the focus of making tea products rather than taste in today's tea organoleptic evaluation in Taiwan (see Table 1).

In addition to organoleptic evaluation, including tea farm management and tea-making process mechanisms not only can provide a more comprehensive model for the tea evaluation system but can also improve the objectivity of such system. The findings of this study provide academia and practitioners with insightful information to enhance the current tea appraisal system.

\subsection{Limitations and Future Research}

This study focuses on Taiwan's tea assessment system. All experts from the perspectives of Taiwan tea culture were asked to evaluate the whole tea processing system from tea cultivation to production, so the generalizability of this study might be limited. Future researchers may consider following the procedure of this study to interview native experts and find a suitable tea assessment system for their own evaluation mechanism to meet their cultural and environmental specifications.

Author Contributions: Y.-Y.C. and G.-J.W. collected the data, conducted the data analyses. H.-H.F. interpreted the results, wrote and reviewed the manuscript critically. All authors have read and agreed to the published version of the manuscript.

Funding: This research received no external funding.

Conflicts of Interest: The authors declare no conflict of interest.

\section{References}

1. A cultural History of Tea in China. Available online: https://theculturetrip.com/asia/china/articles/a-culturalhistory-of-tea-in-china/ (accessed on 17 November 2018).

2. History of Tea in Taiwan. Available online: https://taiwanleaftea.com/info/history-of-tea-in-taiwan (accessed on 12 July 2020).

3. Kembel, N. Taiwan in the Eyes of a Foreigner; Tsai's Idea Co.: Xin Zhu, China, 2011.

4. Huang, P.Y.; Lien, Y.H. Mobility, bordering, and the contested localness of the tea trade between Taiwan and Vietnam. Cult. Stud. 2018, 27, 87-126.

5. Does Taiwan Make the Best Tea in the World? Available online: https://theculturetrip.com/asia/taiwan/ articles/does-taiwan-make-the-best-tea-in-the-world (accessed on 7 January 2019).

6. Tea Competitions in Taiwan. Available online: https://taiwanleaftea.com/info/tea-competitions-in-taiwan (accessed on 22 July 2020).

7. Hsieh, T.Y.; Lu, S.T.; Tzeng, G.H. Fuzzy MCDM approach for planning and design tenders selection in public office buildings. Int. J. Proj. Manag. 2004, 22, 573-584. [CrossRef]

8. Tsai, H.C.; Lee, A.S.; Lee, H.N.; Chen, C.N.; Liu, Y.C. An Application of the Fuzzy Delphi Method and Fuzzy AHP on the Discussion of Training Indicators for the Regional Competition, Taiwan National Skills Competition, in the Trade of Joinery. Sustainability 2020, 12, 4290. [CrossRef]

9. Altintas, K.; Vayvay, O.; Apak, S.; Cobanoglu, E. An Extended GRA Method Integrated with Fuzzy AHP to Construct a Multidimensional Index for Ranking Overall Energy Sustainability Performances. Sustainability 2020, 12, 1602. [CrossRef]

10. Moslem, S.; Ghorbanzadeh, O.; Blaschke, T.; Duleba, S. Analyzing Stakeholder Consensus for a Sustainable Transport Development Decision by the Fuzzy AHP and Interval AHP. Sustainability 2019, 11, 3271. [CrossRef]

11. Cultivation environment of Tea Plants-Council of Agriculture, Executive Yuan, Taiwan. Available online: https://www.youtube.com/watch?v=0SaWi1M5j14\&feature=youtu.be (accessed on 16 August 2018).

12. Tea Plants and Environment- Council of Agriculture, Executive Yuan, Taiwan. Available online: https: //kmweb.coa.gov.tw/subject/subject.php?id=7154 (accessed on 19 May 2020). 
13. Tea in Taiwan: A Complete Guide. Available online: https://www.nickkembel.com/tea-in-taiwan/ (accessed on 30 April 2018).

14. Tea Growing Environment (Chinese Version) Tea Research and Extension Station, COA. Available online: https://www.tres.gov.tw/ws.php?id=1669 (accessed on 13 July 2020).

15. Liu, H. Tea Cultivation and Primary Processing (Chinese version); Wuzhou Publisher: Taipei, Taiwan, 2014.

16. Pan, S.Y. Secrete of fertilization for plants (Chinese version). Sci. Dev. 2018, 545, 6-9.

17. Wang, C.H. Soil and fertilizer strategic management for organic. Sustain. Agric. 2018, 39, 48-57.

18. The Effects of Promotion for Tea Health Management Area (Chinese Version). Institutional Repository, Taiwan Agriculture Research Institute. Available online: http://ir.tari.gov.tw:8080//handle/345210000/6596 (accessed on 2 November 2018).

19. Agro-Pesticides Management Act: Article 1. Council of Agriculture, Executive Yuan, Taiwan. Available online: https://law.coa.gov.tw/GLRSnewsout/EngLawContent.aspx?lan=E\&id=303 (accessed on 23 May 2018).

20. Damalas, C.A.; Eleftherohorinos, I.G. Pesticide exposure, safety issues, and risk assessment indicators. Int. J. Environ. Res. Public Health 2011, 8, 1402-1419. [CrossRef]

21. Chen, H.Y.; Huang, Y.C. Safety standard of pesticide application and executive action. Agric. Policy Rev. 2002, 120, 53-58.

22. Tea Theme Pavilion. Council of Agriculture, Executive Yuan, Taiwan. 2016. Available online: https://kmweb. coa.gov.tw/subject/lp.asp?ctNode $=9822 \& C t U n i t=5845 \& B a s e D S D=7 \& m p=86$ (accessed on 6 December 2016).

23. Wu, L.Y.; Hwang, L.S. Food and life: Tea and health. Sci. Dev. 2004, 384, 18-23.

24. Ho, H.F. Main points of oolong's quality evaluation. Tea News 2001, 5, 89-91.

25. Global Tea Evaluation Method and Process. 2016. Available online: https://teatalkacademy.com/index.php/ celebrities/13-tang-jia-hong/78-c3m201606-2 (accessed on 1 January 2016).

26. Competition Tea: Rationality and Sensibility of Tea in Taiwan. Rhythms Monthly Magazine. 2012, p. 167. Available online: http://www.rhythmsmonthly.com/?p=12693 (accessed on 1 June 2012).

27. Tea Arts. 2012. Available online: http://teaarts.blogspot.com/2012/03/chinese-english-tea-studies-terminology. hml (accessed on 1 March 2012).

28. Lin, G.Y. The evolution of tea competition in Lugu township farmers' association. Lugu Townsh. Farmers' Assoc. Forum 2002, 7, 75-80.

29. Chen, Y.C.; Lee, C.S. Constructing an evaluation model of agricultural tourism production value with a Fuzzy AHP approach. Survey Res. Method Appl. 2018, 41, 57-86.

30. Çebi, A.; Karal, H. An application of fuzzy analytic hierarchy process (FAHP) for evaluating students' project. Ed. Res. Rev. 2017, 12, 120-132.

31. Fu, H.H.; Tzeng, S.Y. Applying fuzzy multiple criteria decision making approach to establish safety-management system for hot spring hotels. Asia Pac. J. Tour. Res. 2016, 21, 1343-1356. [CrossRef]

32. Zadeh, L.A. The concept of a linguistic variable and its application to approximate reasoning-I. Inform. Sci. 1975, 8, 199-249. [CrossRef]

33. Baby, S. AHP modeling for multicriteria Decision-Making and to optimize Strategies for Protecting Coastal Landscape Resources. Int. J. Innov. Manag. 2013, 4, 218-227.

34. Saaty, T.L. A scaling method for priorities in hierarchical structure. J. Math. Psychol. 1977, 15, $234-281$. [CrossRef]

35. Basaran, B. A Critique on the Consistency Ratios of Some Selected Articles Regarding Fuzzy AHP and Sustainability. In Proceedings of the 3rd International Symposium on Sustainable Development, Sarajevo, Bosnia and Herzegovina, 31 May-1 June 2012.

36. Saaty, T.L. The Analytic Hierarchy Process; McGraw-Hill: New York, NY, USA, 1980.

37. Shi, J.L.; Wang, Y.J.; Jin, H.H.; Fan, S.J.; Ma, Q.Y.; Zhou, M.J. A Modified Method for Risk Evaluation in Failure Mode and Effects Analysis. J. Appl. Sci. Eng. 2016, 19, 177-186.

38. Nurani, A.I.; Pramudyaningrum, A.T.; Fadhila, S.R.; Sangadji, S.; Hartono, W. Analytical Hierarchy Process (AHP), Fuzzy AHP, and TOPSIS for Determining Bridge Maintenance Priority Scale in Banjarsari, Surakarta. Int. J. Sci. Appl. Sci. Conf. Ser. 2017, 2, 60-71. [CrossRef]

39. Mon, D.L.; Cheng, C.H.; Lin, J.C. Evaluating weapon system using fuzzy analytic hierarchy process based on entropy weight. Fuzzy Sets Syst. 1994, 62, 127-134. [CrossRef]

40. Buckley, J.J. Fuzzy hierarchical analysis. Fuzzy Sets Syst. 1985, 17, 233-247. [CrossRef] 
41. Rahmani, A.; Hosseinzadeh Lotfi, F.; Rostamy-Malkhalifeh, M.; Allahviranloo, T. A new method for defuzzification and ranking of fuzzy numbers based on the statistical beta distribution. Adv. Fuzzy Syst. 2016. [CrossRef]

42. Tseng, T.L.B.; Konada, U.; Kwon, Y.J. A novel approach to predict surface roughness in machining operations using fuzzy set theory. J. Comput. Des. Eng. 2016, 3, 1-13. [CrossRef]

43. Talon, A.; Curt, C. Selection of appropriate defuzzification methods: Application to the assessment of dam performance. Expert Syst. Appl. 2017, 70, 160-174. [CrossRef]

44. Braae, M.; Rutherford, D.A. Fuzzy relations in a control setting. Kybernetes 1978, 7, 185-188. [CrossRef]

45. Runkler, T.A.; Glesner, M. A set of axioms for defuzzification strategies towards a theory of rational defuzzification operators. In Proceedings of the 2nd IEEE International Conference Fuzzy Systems, San Francisco, CA, USA, 8-12 March 1993; pp. 1161-1166.

46. Association of Taiwan Tea. The Website of Association of Taiwan Tea. 2019. Available online: http: //att.org.tw/home2/9895/ (accessed on 26 March 2019).

(C) 2020 by the authors. Licensee MDPI, Basel, Switzerland. This article is an open access article distributed under the terms and conditions of the Creative Commons Attribution (CC BY) license (http://creativecommons.org/licenses/by/4.0/). 